\title{
Clinical characteristics of patients with re-admitted of novel coronavirus 2019 (nCOVID-19) in Wenzhou, China
}

\author{
Yuping Yuan ${ }^{1}$, Xinchun $\mathrm{Ye}^{1}$, Risheng Huang ${ }^{1}$, Aiqiong Cheng ${ }^{1}$, Zhijie $\mathrm{Yu}^{2}$, Ziyang Huang ${ }^{2}$, \\ Rongrong Chen ${ }^{2}$, Xiangao Jiang ${ }^{1}$, Yuanliang Zheng ${ }^{1}$, and Jichan Shi ${ }^{1}$ \\ ${ }^{1}$ Wenzhou Central Hospital \\ ${ }^{2}$ The First Affiliated Hospital of Wenzhou Medical University
}

May 7, 2020

\begin{abstract}
Background: As the COVID-19 became a world wild infectious emergency, most of patients are cured and discharged. However, some patients are re-admitted due to re-fever, or the PCR test re-positive. To find out whether it is necessary to take them readmitted, especially the asymptomatic patients, we summarize and analyze the clinical and treatment characteristics of patients with "re-admission" of COVID-19 during twice hospitalizations. Methods: 141 cases with COVID-19 admitted to Wenzhou Central Hospital from January 17, 2020 to March 5, were followed up until March 30. There were 12 patients re-admitted. Data were collected, including clinical records,lab indexes, $\mathrm{CT}$ and treatment strategy. The differences were analyzed. Results: Most patients had good results. Totally $12(8.5 \%)$ were re-admitted. $1(8.3 \%)$ had fever,high WBC and progressive CT changes,1 had increased transaminase; the PCR re-tests of these two patients were negative. Another 10 patients were admitted due to PCR test positive, 7 of which were clinical asymptomatic. Compared with 1st discharging, CT imaging of all was significantly improved. All re-admissions did not need oxygen inhalation or mechanical ventilation. Conclusions: The prognosis of patients re-admitted were good, and no serious cases. Staying at home or concentrated medical observation, is a safe and feasible method, if the patient has a positive PCR test and the clinical symptoms are not serious. During medical observation, patients with underlying diseases should be focused on, and most do not need to be re-admitted.
\end{abstract}

Title: Clinical characteristics of patients with re-admitted of novel coronavirus 2019 (nCOVID19) in Wenzhou, China

\section{Running title: A review of re-admitted patients of COVID-19}

Authors: Yuan. Yuping ${ }^{1 \#}$; Ye. Xinchun ${ }^{2} \#$; Huang. Risheng ${ }^{3}$; Cheng. Aiqiong ${ }^{2}$; Yu. Zhijie ${ }^{4}$ Huang. Ziyang $^{4}$; Chen. Rongrong ${ }^{4}$; Jiang. Xiangao ${ }^{2}$; Zheng. Yuanliang ${ }^{3 *}$; Shi. Jichan ${ }^{2 *}$.

\section{Affiliations}

1 Departments of Gastroenterology, Wenzhou Central Hospital, Wenzhou, China

2 Departments of Infectious Disease, Wenzhou Central Hospital, Wenzhou, China

3 Departments of Thoracic Surgery, Wenzhou Central Hospital, Wenzhou, China

4 Department of Hematology, Wenzhou Key Laboratory of Hematology, The First Affiliated Hospital of Wenzhou Medical University, Wenzhou, China.

\# contributed equal to this work

* correspond authors 
Correspond authors and E-mail: S. Jichan, shijichan@163.com

Co-Correspond authors and E-mail: Z. Yuanliang, 610070446@qq.com

\section{Author Contributions:}

Y. Yuping and Y. Xinchun contribute equally to this work., wrote the original draft. H. Risheng; C. Aiqiong collected data of epidemics, clinical features, laboratory indexes, Chest CTs and Electrocardiography. Y. Zhijie; H. Ziyang; C. Rongrong did data analysis, J. Xiangao support funding, Z. Yuanliang lead the project administration, S. Jichan super revised manuscript and supervised the work.

\section{Conflict of Interest Statement:}

The authors declared that they have no conflict of interest to this work.

\section{Financial support}

This work was supported by Zhejiang Province Key R \& D Plan Emergency Project (2020C03123), and Wenzhou Science and Technology Major Special Projects (ZY202004).

\section{Abstract:}

\section{Background:}

As the COVID-19 became a world wild infectious emergency, most of patients are cured and discharged. However, some patients are re-admitted due to re-fever, or the PCR test re-positive. To find out whether it is necessary to take them re-admitted, especially the asymptomatic patients, we summarize and analyze the clinical and treatment characteristics of patients with "re-admission" of COVID-19 during twice hospitalizations.

\section{Methods:}

141 cases with COVID-19 admitted to Wenzhou Central Hospital from January 17, 2020 to March 5, were followed up until March 30. There were 12 patients re-admitted. Data were collected, including clinical records,lab indexes, $\mathrm{CT}$ and treatment strategy. The differences were analyzed.

\section{Results:}

Most patients had good results. Totally $12(8.5 \%)$ were re-admitted. 1 (8.3\%) had fever,high WBC and progressive $\mathrm{CT}$ changes, 1 had increased transaminase; the PCR re-tests of these two patients were negative. Another 10 patients were admitted due to PCR test positive, 7 of which were clinical asymptomatic. Compared with 1st discharging, CT imaging of all was significantly improved. All re-admissions did not need oxygen inhalation or mechanical ventilation.

\section{Conclusions:}

The prognosis of patients re-admitted were good, and no serious cases. Staying at home or concentrated medical observation, is a safe and feasible method, if the patient has a positive PCR test and the clinical symptoms are not serious. During medical observation, patients with underlying diseases should be focused on, and most do not need to be re-admitted.

\section{Key words:}

COVID-19; new coronavirus pneumonia;Clinical characteristics;Re-admitted

\section{Introduction}

Since December 8, 2019, an unexplained pneumonia case was discovered in Wuhan City ${ }^{1}$. The first coronavirus was isolated on January 7, 2020, and the virus was subsequently named COVID-19 by WHO ${ }^{2}$. The virus is currently worldwide Widely spread within the country. On January 17, 2020, Wenzhou confirmed the first new case of coronavirus pneumonia in Zhejiang Province. Wenzhou is also the first city other than 
Hubei Province to have more than 500 confirmed cases. From the first patient admitted on January 17 to March 5, a total of 141 patients were admitted to our hospital. All the diagnosed patients were cured and discharged according to the discharge standards set by the country, and no deaths occurred.

As the current epidemic situation in China continues to improve, most of patients are cured and discharged. We have found in clinical work that some patients who have been discharged have fever again, or the PCR test is positive again , and were admitted to hospital secondly. For this part of the patients, especially the asymptomatic patients, there has not been any relevant clinical research reports now whether it is really necessary to be admitted to the hospital for treatment again, or only necessary to take home medical observation. Combined with the follow-up and re-examination results of patients discharged from our hospital, we summarize and analyze the clinical characteristics, treatment options and prognosis of patients who were "re-admitted" during the first and second hospitalization.

\section{Materials and Methods:}

Retrospective analysis of confirmed 141 cases of new coronary pneumonia admitted in our hospital from January 17, 2020 to March 5, 2020 (pharyngeal swab test for SARS-Cov-2 positive). In total 141 patients median age was 46.0 years (34.0-55.0). In gender, 68 were female $(48.2 \%)$ and 73 were male $(51.8 \%)$. There were 48 patients $(39.7 \%)$ who had been to Wuhan within two weeks and $13(9.2 \%)$ patients had smoking history . 25 patients $(17.7 \%)$ were severe or critical cases. The average number of days for the first hospitalization is about 22 days, 58 patients (41.1\%) with underlying diseases, 140 patients (99.3) had infectious lesions on CT, and 44 patients $(31.2 \%)$ had lower WBC than normal at the time of admission, 96 ( $68.1 \%)$ The patient's white blood cell value is normal, only $1(0.7 \%)$ patient's WBC is higher than the normal. 56 patients with low lymphocytes, no patients had high absolute lymphocytes count. All patients had at least one clinical symptom for the first hospitalization, and all were treated with antiviral drugs during hospitalization. The study was approved by the ethics committee of Wenzhou Central Hospital and the informed consent of the participants was obtained.

\section{Observation index:}

Age, gender, smoking history, Wuhan exposure history, number of severe and critically cases, days of hospitalization, combined with underlying diseases, clinical symptoms, CT characteristics,lab indexes (including chest CT, white blood cell and Lymphocytes), treatment plans. The treatment plans included oxygen inhalation, mechanical ventilation, hemodialysis, antibiotics, antiviral and hormones. The clinical symptoms and treatment plans of 12 re-admitted patients during the second hospitalization.

\section{Statistical methods:}

Statistical analysis was performed using SPSS25.0 software. The quantile method was used to measure the age of the data, and the mean \pm standard deviation was used for the length of hospitalization. All counting data were described using percentage $(\%)$.

\section{Results}

\section{General clinical information:}

The clinical characteristics of the first hospitalization of 141 patients are shown in Table 1 . The median age of 12 re-admission patients was 52.5 (39.3-57.0), which was significantly higher than the age of non-readmission patients 46.0 (32.5-54.5). The average days of hospitalization $(28.2 \pm 8.3)$ was also longer than those who were not re-admitted to hospital $(21.7 \pm 7.9)$. Only 1 patient $(8.3 \%)$ was severe case. There were 6 patients $(50 \%)$ with underlying diseases and 7 patients $(58.3 \%)$ required oxygen therapy. No patients required mechanical ventilation. 7 patients $(58.3 \%)$ had used prophylactic antibiotics and 2 patients $(16.7 \%)$ had used hormone therapy for a short time. All patients received antiviral therapy.

\section{Clinical indexes andChest CT:}

Lab indexes and CT characteristics of 141 patients were collected and shown in Table 2,Including first 
admission, discharge, and first review after discharge ones. The detailed results of the 12 patients, who were re-admitted to the hospital,during the first hospitalization are shown in Figure 1A. 12 patients (100\%) had infectious lung lesions, mainly ground glass lesions, and both lungs were involved to varying degrees. In 3 cases (25\%), the absolute values of white blood cells and lymphocytes were lower than normal, and no patients had high white blood cells. The results of the 12 re-admitted patients on the first discharge were as follows:At this time, only $8(66.7 \%)$ patients still had infectious lesions on CT, but the infectious lesions of the lungs was obviously absorbed compared to the those at the first hospitalization, only $1(8.3 \%)$ patient's leukocytes were lower than normal, and $2(16.7 \%)$ patients had absolute lymphocyte values lower than normal. No absolute leukocytes and lymphocytes were found higher than normal.

The first results of the re-examination after discharged from hospital were as follows: 5 patients $(41.7 \%)$ still had lung infectious lesions, and only 1 patient (8.3\%) had progressive lung infectious lesions compared to discharge before, and this patient's white blood cells were higher than normal, combining with bacterial infection may cause the result. The rests had much better smaller infectious lesions than discharged from hospital, and the white blood cell values returned to normal. The details of the second hospitalization are shown in Figure 1B. The CT imaging findings of the 12 re-admitted patients during the entire hospitalization are shown in Figure 1C-D.

\section{Discussion}

At present, the world's new coronary pneumonia is currently in a pandemic worldwide with more than 3 million confirmed cases and about 200000 deaths $^{3}$. In some countries with severe epidemics, the medical system is facing a severe challenge. How to alleviate the current limited resources of medical treatment is an urgent problem that all countries need to solve. Except for increasing medical investment,formulating discharge standards which in accordance with the national conditions of the country in a special period can reduce the number of hospitalized patients and alleviate the current shortage of medical resources.

With the increasing number of curing patients, the management of patients after discharge will be the focus of sometime in the future, which includes follow-up time, follow-up testing items and when they can return to normal life. China's current diagnosis and treatment guidelines recommend returning to re-examination in 2 and 4 weeks after discharge. Follow-up examination items generally include blood routine, throat swab PCR test and chest CT. The follow-up time of patients in our hospital after discharge is week 1 , week 2 and week 4. Reviewing the 12 re-admitted patients in this study, no clinical complications occurred during home or concentrated medical observation, and $6(50 \%)$ patients had more than one underlying disease •In general, patients with basic diseases have a higher proportion of "re-admissions", and more attention should be paid to these patients.

Only one patient had a fever, and patient's chest CT lesions have progressed from the time of discharge, and the white blood cells, neutrophils, and CRP were significantly increased,which may be caused by bacterial infection this time, regardless this patient was negative for PCR test after re-admission. Another patient had nausea and vomiting symptoms, and the transaminase increased significantly when he was returned to the hospital. The PCR test was negative multiple times after re-admission, considering that this patient has a history of chronic hepatitis B, and had taken a longer period of antiviral drugs during the first hospitalization. These two patients with negative PCR tests had basic diseases, which also suggested that although patients were cured and discharged, the immunity had not fully recovered。Those who with basic diseases should pay more attention to rest, which was also the object of close attention during medical observation.

The remaining 10 patients were positive for PCR tests during the re-examination, of which only 3 patients had cough. All 10 patients did not receive oxygen and the oxygen saturation was higher than $95 \%$, and the chest CT inflammation was significantly better than what they discharged from the hospital. WBC and lymphocytes also returned to normal. It is recommended that if the patient does not have shortness of breath, fever, cough, or increased sputum during the observation period, there is no need to go to the hospital for weekly review, especially in regions or countries with tight medical resources, which can partially ease the situation of shortage of medical resources. 
Because Coronavirus pneumonia is a new type of viral pneumonia, understanding of the evolution of its condition needs to be deepened. There is currently no evidence that patients who are cured will not infect others, so it is recommended that medical observation should be required for 14 days after discharge. According to the recent report, there may be no live virus in sputum after 8 days of symptoms presented, meanwhile as in the stool and blood ${ }^{4}$. In our study, the average of first hospitalization of 141 cases admitted by our hospital was 22 days, the shortest was more than 8 days, only 12 patients $(8.5 \%)$ were re-admitted to the hospital, and only 2 patients $(1.4 \%)$ were due to symptoms worsen caused by bacterial infection, and there was no life-threatening; the rest of patients were re-admitted because of positive PCR test, but had no infectious, consistent with another study, which reported patients may still be virus carriers with PCR test positive 5-13 days after discharged, but no family members were infected during home quarantine ${ }^{5}$. For patients who were cured for 14 days, if the PCR re-test was negative, the patient should be returned to normal life and it is safe to choose home or centralized medical observation. According to the follow-up of this study, there have been no reports of related patients reappearing "re-positive" or infected others, but it is recommended that patients should continue to wear protective masks and avoid going to places with dense personnel or poor ventilation.

Different from re-admitted patients, the asymptomatic infected patients may be new breaking point. Patients with mild symptoms or even asymptomatic phase may had the most infectious ${ }^{4}$. To enhanced the management of asymptomatic infections, the Chinese State Council issued "the Protocol for the management of novel coronavirus asymptomatic infected persons" on April $6^{\text {th6 }}$ : the asymptomatic infections shall take concentrated medical quarantine for 14 days, and turned to be confirm cases once the patients presented the symptoms related to COVID-19 during quarantine period. Continuous PCR test with interval more than $24 \mathrm{~h}$ would be taken after 14 days quarantine. If the results were continuous negative in twice test, then released; otherwise, extend the quarantining days until met the criterial of quarantine release.

Studies have reported that the widespread use of glucocorticoids is not recommended at present, and severe patients need to be cautious to use low- to medium-dose short-term glucocorticoid ${ }^{7}$. While another study showed that there was currently no evidence to support that patients with Coronavirus pneumonia would benefit from hormone therapy and may increase the associated risk ${ }^{8}$. Of the 141 patients in our hospital, only $10(7.1 \%)$ patients had been used hormones for a short period of time, and none had caused serious adverse reactions. Among the 12 patients who were re-admitted to the hospital, one patient with a positive PCR re-test had used hormones for a short time, while another patient had used hormones but the PCR re-test was negative.

In the early stage, some scholars proposed that since the ratio of "re-admission" was so high, it need to be considered whether it is was necessary to raise the discharge standards ${ }^{9}$. All the re-admitted patients in our hospital had good prognosis, and none of them had related complications. The current discharge standard in China is that continuous twice PCR tests are negative, the interval between tests longer than 24 hours, the respiratory symptoms have relieved significantly, the temperature has returned to normal for more than 3 days, and CT imaging shows that the lesions have improved significantly ${ }^{10}$. However, according to this discharge standard, we find that the average of hospitalization is too long. The average length of first hospitalization is about 22 days. In fact, many patients have no obvious symptoms in the late stage of hospitalization, and CT imaging has also improved. It is only a positive PCR test that restricts them to get the discharge standards which increases the strain on medical resources. Since the serious epidemic situation in many countries, can we consider lowering the discharge standard? When the clinical symptoms relieve significantly, allow mild patients to be discharged early, take home or concentrated isolation, and let family doctors conduct medical observations and monitor general vital signs, if possible. This may be a way to alleviate medical tensions in some countries with severe epidemics. And this may also give advice for the countries who controlled pandemic well, they could slope the attentions and medical resources into supervising the asymptomatic infected, which may help to control the source of infection. Of course, this is only recommendation based on the analysis of the limited case data in our hospital. The specific plan still needs to be comprehensively considered in accordance with the national conditions of each country and the severity of the epidemic situation, and formulate discharge standards that conform to the country. 
In summary, countries with serious epidemics and tight medical resources can formulate discharge standards that meet their national conditions, especially when the patients' clinical symptoms,lab indexes and CT imaging results have improved significantly but the PCR test is still positive. Patients can be advised to be discharged from the hospital but need to take home or concentrated medical observation for 14 days. If the PCR test is negative during the re-examination, the patient should be returned to normal life, but it is recommended that the patient should continue to wear protective masks to avoid crowding and ventilation Bad places. If the patient's re-examination after discharge is still positive, continue to take 14 days of home or concentrated medical observation, and hospitalization is not required, which is a safe, feasible, and effective method. This is a safe, feasible, and effective method, which can reduce the strain on medical resources to a certain extent.

\section{Reference}

1. Zhu N, Zhang D, Wang W, et al. A Novel Coronavirus from Patients with Pneumonia in China, 2019. $N$ Engl J Med . Feb 20 2020;382(8):727-733. doi:10.1056/NEJMoa2001017

2. WHO Director-General's remarks at the media briefing on 2019-nCoV on 11 February 2020. . World Health Organization (2020) Feb 11, 2020. Accessed Feb 25,2020.https://www.who.int/dg/speeches/detail/who-director-general-s-remarks-at-the-media-briefingon-2019-ncov-on-11-february-2020.

3. Coronavirus disease (COVID-19) Situation dashboard . 2020. April 30. Accessed April 30.https://covid19.who.int/

4. Wolfel R, Corman VM, Guggemos W, et al. Virological assessment of hospitalized patients with COVID2019. Nature . Apr 1 2020;doi:10.1038/s41586-020-2196-x

5. Lan L, Xu D, Ye G, et al. Positive RT-PCR Test Results in Patients Recovered From COVID-19. JAMA . Feb 27 2020;doi:10.1001/jama.2020.2783

6. coucil JpacmfnciwC-oCs. Protocol for the management of novel coronavirus asymptomatic infected persons. 2020.

7. Shang L, Zhao J, Hu Y, Du R, Cao B. On the use of corticosteroids for 2019-nCoV pneumonia. Lancet . Feb 29 2020;395(10225):683-684. doi:10.1016/S0140-6736(20)30361-5

8. Russell CD, Millar JE, Baillie JK. Clinical evidence does not support corticosteroid treatment for 2019nCoV lung injury. Lancet . Feb 15 2020;395(10223):473-475. doi:10.1016/S0140-6736(20)30317-2

9. Zhou L, Liu K, Liu HG. [Cause analysis and treatment strategies of "recurrence" with novel coronavirus pneumonia (covid-19) patients after discharge from hospital]. Zhonghua Jie He He Hu Xi Za Zhi . Mar 2 2020;43(0):E028. doi:10.3760/cma.j.cn112147-20200229-00219

10. China NHCotPsRo. Diagnosis and treatment of pneumonia caused by novel coronavirus infection (Trial version 7). 2020 .

Table 1. clinical characteristic of the study patients

\begin{tabular}{llll}
\hline & & $\begin{array}{l}\text { The first } \\
\text { hospitalization }\end{array}$ & $\begin{array}{l}\text { The first } \\
\text { hospitalization }\end{array}$ \\
\hline characteristics & All patients $(\mathrm{n}=141)$ & Re-admission $(\mathrm{n}=12)$ & $\begin{array}{l}\text { Not re-admission } \\
(\mathrm{n}=129)\end{array}$ \\
$\begin{array}{l}\text { Median age (IQR, } \\
\text { year) }\end{array}$ & $46.0(34.0-55.0)$ & $52.5(39.3-57.0)$ & $46.0(32.5-54.5)$ \\
$\begin{array}{l}\text { Female sex (\%) } \\
\text { Smoking history }(\%)\end{array}$ & $68(48.2)$ & $5(41.7)$ & $63(48.8)$ \\
& $13(9.2)$ & $3(25.0)$ & $10(7.8)$
\end{tabular}




\begin{tabular}{|c|c|c|c|}
\hline & & $\begin{array}{l}\text { The first } \\
\text { hospitalization }\end{array}$ & $\begin{array}{l}\text { The first } \\
\text { hospitalization }\end{array}$ \\
\hline $\begin{array}{l}\text { Exposure history in } \\
\text { Wuhan }<2 \text { weeks }(\%)\end{array}$ & $48(39.7)$ & $4(33.3)$ & $44(34.1)$ \\
\hline $\begin{array}{l}\text { Severe or critical cases } \\
(\%)\end{array}$ & $25(17.7)$ & $1(8.3)$ & $24(18.6)$ \\
\hline $\begin{array}{l}\text { Hospital stays (mean } \pm \\
\text { standard deviation) }\end{array}$ & $22.2 \pm 8.1$ & $28.2 \pm 8.3$ & $21.7 \pm 7.9$ \\
\hline Coexisting disorder $(\%)$ & $58(41.1)$ & $6(50)$ & $52(40.3)$ \\
\hline Hypertension & $37(26.2)$ & $4(33.3)$ & $33(25.6)$ \\
\hline Diabetes & $11(7.8)$ & $1(8.3)$ & $10(7.8)$ \\
\hline Chronic liver disease & $15(10.6)$ & $2(16.7)$ & $13(10.1)$ \\
\hline Chronic kidney disease & $2(1.4)$ & 0 & $2(1.6)$ \\
\hline $\begin{array}{l}\text { Chronic obstructive } \\
\text { pulmonary }\end{array}$ & $3(2.1)$ & $1(8.3)$ & $2(1.6)$ \\
\hline $\begin{array}{l}\text { Malignant tumor } \\
\text { symptoms }(\%)\end{array}$ & $1(0.7)$ & $1(8.3)$ & 0 \\
\hline Fever & $109(77.3)$ & $8(66.7)$ & $101(78.3)$ \\
\hline Cough & $84(59.6)$ & $8(66.7)$ & $76(58.9)$ \\
\hline Sore throat & $16(11.3)$ & $3(25.0)$ & $13(10.1)$ \\
\hline Shortness of breath & $19(13.5)$ & $1(8.3)$ & $18(14.0)$ \\
\hline $\begin{array}{l}\text { Diarrhea } \\
\text { Medication (\%) }\end{array}$ & $16(11.3)$ & $2(16.7)$ & $14(10.9)$ \\
\hline Oxygen inhalation & $64(45.4)$ & $7(58.3)$ & $57(44.2)$ \\
\hline Need ventilator & $3(2.1)$ & 0 & $3(2.3)$ \\
\hline $\begin{array}{l}\text { Continuous renal } \\
\text { replacement therapy }\end{array}$ & $2(1.4)$ & 0 & $2(1.5)$ \\
\hline Using glucocorticoids & $19(13.5)$ & $2(16.7)$ & $17(13.2)$ \\
\hline $\begin{array}{l}\text { Using antibiotics } \\
\text { Using antiviral }\end{array}$ & $51(36.2)$ & $7(58.3)$ & $44(34.1)$ \\
\hline $\begin{array}{l}\text { Recombinant Human } \\
\text { interferon ?2b }\end{array}$ & $141(100)$ & $12(100)$ & $129(100)$ \\
\hline Arbidol Tablets & $112(79.4)$ & $7(58.3)$ & $105(81.4)$ \\
\hline $\begin{array}{l}\text { Lopinavir and } \\
\text { Ritonavir Tablets }\end{array}$ & $136(96.5)$ & $12(100)$ & $124(96.1)$ \\
\hline
\end{tabular}

Table 2. Radiographic and laboratory findings

\begin{tabular}{llll}
\hline $\begin{array}{l}\text { Different stages of } \\
\text { hospitalization }\end{array}$ & All patients $(\mathrm{n}=141)$ & Readmission $(\mathrm{n}=12)$ & $\begin{array}{l}\text { Not re-admission } \\
(\mathrm{n}=129)\end{array}$ \\
\hline $\begin{array}{l}\text { First hospitalization } \\
\text { Abnormalities on chest }\end{array}$ & $\begin{array}{l}\text { First hospitalization } \\
140(99.3)\end{array}$ & $\begin{array}{l}\text { First hospitalization } \\
12(100)\end{array}$ & $\begin{array}{l}\text { First hospitalization } \\
128(99.2)\end{array}$ \\
$\begin{array}{l}\text { CT } \\
\text { White-cell count }\end{array}$ & & \\
$<4.0 \times 10^{9} / \mathrm{L}$ & & \\
$\begin{array}{l}4.0-10.0\left(\times 10^{9} / \mathrm{L}\right) \\
>10.0 \times 10^{9} / \mathrm{L}\end{array}$ & $44(31.2)$ & $3(25.0)$ & $41(31.8)$ \\
$\begin{array}{l}\text { Lymphocyte count } \\
<1.1 \times 10^{9} / \mathrm{L}\end{array}$ & $1(0.7)$ & $9(75.0)$ & $87(67.4)$ \\
$1.1-3.2\left(\times 10^{9} / \mathrm{L}\right)$ & $56(39.7)$ & 0 & $1(0.8)$ \\
& $85(60.2)$ & $3(25.0)$ & $53(41.1)$ \\
& & $9(75.0)$ & $76(58.9)$
\end{tabular}




\begin{tabular}{|c|c|c|c|}
\hline $\begin{array}{l}\text { Different stages of } \\
\text { hospitalization }\end{array}$ & All patients $(\mathrm{n}=141)$ & Readmission $(\mathrm{n}=12)$ & $\begin{array}{l}\text { Not re-admission } \\
(\mathrm{n}=129)\end{array}$ \\
\hline$>3.2 \times 10^{9} / \mathrm{L}$ & 0 & 0 & 0 \\
\hline First discharge & First discharge & First discharge & First discharge \\
\hline $\begin{array}{l}\text { Abnormalities on chest } \\
\text { CT }\end{array}$ & $79(56.0)$ & $8(66.7)$ & $71(55.0)$ \\
\hline \multicolumn{4}{|l|}{ White-cell count } \\
\hline$<4.0 \times 10^{9} / \mathrm{L}$ & $6(4.3)$ & $1(8.3)$ & $5(3.9)$ \\
\hline $4.0-10.0\left(\times 10^{9} / \mathrm{L}\right)$ & $135(95.7)$ & $10(83.3)$ & $124(96.1)$ \\
\hline$>10.0 \times 10^{9} / \mathrm{L}$ & 0 & $1(8.3)$ & 0 \\
\hline \multicolumn{4}{|l|}{ Lymphocyte count } \\
\hline$<1.1 \times 10^{9} / \mathrm{L}$ & $9(6.4)$ & $2(16.7)$ & $7(5.4)$ \\
\hline $1.1-3.2\left(\times 10^{9} / \mathrm{L}\right)$ & $132(93.6)$ & $10(83.3)$ & $122(94.6)$ \\
\hline$>3.2 \times 10^{9} / \mathrm{L}$ & 0 & 0 & 0 \\
\hline $\begin{array}{l}\text { First re-examination } \\
\text { after discharge }\end{array}$ & $\begin{array}{l}\text { First re-examination } \\
\text { after discharge }\end{array}$ & $\begin{array}{l}\text { First re-examination } \\
\text { after discharge }\end{array}$ & $\begin{array}{l}\text { First re-examination } \\
\text { after discharge }\end{array}$ \\
\hline $\begin{array}{l}\text { Abnormalities on chest } \\
\text { CT }\end{array}$ & $57(40.4)$ & $5(41.7)$ & $52(40.3)$ \\
\hline \multicolumn{4}{|l|}{ White-cell count } \\
\hline$<4.0 \times 10^{9} / \mathrm{L}$ & $5(3.5)$ & 0 & $5(3.9)$ \\
\hline $4.0-10.0\left(\times 10^{9} / \mathrm{L}\right)$ & $135(95.7)$ & $11(91.7)$ & $124(96.1)$ \\
\hline$>10.0 \times 10^{9} / \mathrm{L}$ & $1(0.7)$ & $1(8.3)$ & 0 \\
\hline \multicolumn{4}{|l|}{ Lymphocyte count } \\
\hline$<1.1 \times 10^{9} / \mathrm{L}$ & $8(5.7)$ & $2(16.7)$ & $6(4.7)$ \\
\hline $1.1-3.2\left(\times 10^{9} / \mathrm{L}\right)$ & $133(94.3)$ & $10(83.3)$ & $123(95.3)$ \\
\hline$>3.2 \times 10^{9} / \mathrm{L}$ & 0 & 0 & 0 \\
\hline
\end{tabular}

Fig1 Chest CT changes from $1^{\text {st }}$ to $2^{\text {nd }}$ hospitalization of 12 re-admitted patients with COVID19

\section{Legend}

1A. Chest CT of 1st hospitalization. 12 patients (100\%) had infectious lung lesions, mainly ground glass lesions, and both lungs were involved to varying degrees.

1B. Chest CT of 12 re-admitted patients when 2nd hospitalized. 5 patients (41.7\%) still had lung infectious lesions, and only 1 patient (8.3\%) had progressive lung infectious lesions compared to discharge before. The rests had much better smaller infectious lesions than discharged from hospital.

1C. and 1D. Chest CT changes during 2nd hospitalization of 12 re-admitted patients. 


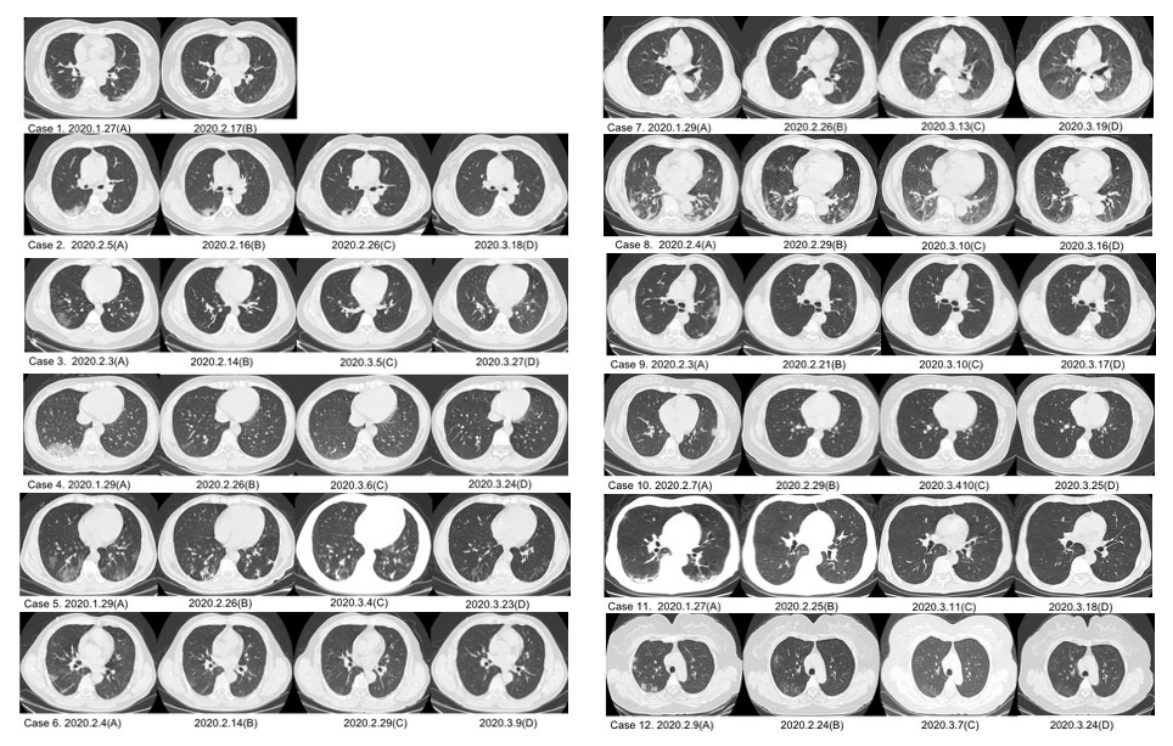

